\title{
"EL AMOR ES ASÍ....", CUENTO \\ CINEMATOGRÁFICO COMO VARIACIÓN DE LA NOVELA LÍRICA DE XAVIER VILLAURRUTIA
}

\author{
"LOVE IS LIKE THAT...": A CINEMATOGRAPHIC SHORT STORY \\ AS A VARIATION OF XAVIER VILLAURRUTIA'S LYRICAL NOVEL
}

\author{
ROSANA RICÁRDEZ ${ }^{*}$
}

RESUMEN: Este artículo analiza el único cuento cinematográfico de Xavier Villaurrutia, "El amor es así...", como parte del proyecto generacional de novela lírica desarrollado junto con los también Contemporáneos Gilberto Owen y Jaime Torres Bodet. Visto así, es la forma en que el autor continúa, por un lado, el proyecto cuyo núcleo es escribir en prosa variaciones de la misma historia y, por el otro, su experimentación estéticoliteraria, resultado tanto de obsesiones temáticas como del encanto por el mundo cinematográfico. Poco a poco, Villaurrutia descubre los recursos del cine hasta el grado de considerarlo junto a otras artes un espacio que hoy se podría llamar "protointermedial".

Palabras Clave: Villaurrutia, novela lírica, cuento cinematográfico, los Contemporáneos, protointermedialidad.

Aвstract: This article analyzes "El amor es así..., the only cinematographic short story written by Xavier Villaurrutia, as part of the generational project undertaken along with his fellow Contemporáneos, Gilberto Owen and Jaime Torres Bodet. Considered in this light, the author is seen as continuing, on the one hand, a project whose objective was to write prose variations of the same story, while on the other hand carrying out the aesthetic-literary experiments inspired by his thematic obsessions and fascination with cinema. Villaurrutia increasingly discovered cinema's potential as a space that, together with other artistic mediums, may be called "proto-intermedial".

KEYwORDs: Xavier Villaurrutia, lyric novel, cinematographic short story, Contemporáneos, proto-intermediality.

Recibido: 28.06.18. Aceptado: 25.10.19.

\footnotetext{
* Doctora ( $\odot$ en Literatura por la Universidad de Chile. Académica de la Universidad Alberto Hurtado, Santiago, Chile. Correo electrónico: rosanaricardez@gmail.com
} 


\section{INTRODUCCIÓN}

- L canon considera la obra de los Contemporáneos producto no de Cun grupo sino de individualidades cuyas intenciones convergen por momentos y permanecen unidas solo como estrategia. No obstante, la relectura contemporánea de esas individualidades lleva a plantear si, más allá de eso, la convergencia de los integrantes proviene acaso de un proyecto artístico que vincula obra y vida hasta desvanecer la frontera común. Las novelas líricas de Owen, Torres Bodet y Villaurrutia mostrarían parte de tal proyecto que, en el caso de este último, prolonga en el poco conocido cuento cinematográfico "El amor es así...".

En "La escena de las novelas líricas en la trayectoria de los Contemporáneos", Betina Keizman (2016) propone que Dama de corazones (Xavier Villaurrutia), Novela como nube (Gilberto Owen) y Margarita de Niebla (Jaime Torres Bodet), conforman un proyecto generacional cuyo núcleo no es escribir prosa sino "escribir en prosa, variaciones de la misma historia" (p. 103) $)^{1}$. Siguiendo esa propuesta, se lleva a cabo una lectura del cuento "El amor es así..." primero como variación de Dama de corazones y, después, como un paso adelante en la experimentación estético-literaria del autor motivado por sus diversas obsesiones temáticas y su fascinación ante el cine, medio cuyos recursos descubre poco a poco hasta considerarlo junto a otras artes en lo que podría llamarse una muy temprana intermedialidad, entendiéndola como espacio de influencia e interacción entre dos o más prácticas artísticas significantes sin relación jerárquica (Cubillo Paniagua, 2013). Digamos, protointermedialidad.

El propio Villaurrutia (1903-1950) no cree mucho en la calidad ni en la prosa de Dama de corazones, sino como medida transitoria. Es así como escribe a Jorge Mañach: "Hasta ahora, yo mismo, en la prosa, no he pretendido sino encontrar palabras adecuadas a una sensibilidad nueva en mí y fuera de mí. Eso quiso ser mi relato (Dama de corazones) no más" (Villaurrutia, 2004, p. 611). Quizás allí esté la explicación para que "El amor es así..." permaneciera inédito hasta después de su muerte; medida precautoria del autor a sabiendas de su "transitorio" valor literario. Pero más allá de lo transitorio, "El amor es así..." puede ser la etapa continua de la experimentación iniciada con la novela lírica, por tanto, una variación del tema.

\footnotetext{
${ }^{1}$ Cursivas en el original.

2 Aunque aquí se asume que la fecha oscila entre 1926 y 1928, la fecha de redacción es imprecisa. Más adelante se aborda el tema.
} 
La crítica sobre Dama de corazones hace eco de la opinión de Octavio Paz (2003), al considerarla "relato (...) que en su tiempo representó una dirección nueva en la prosa de imaginación pero que hoy tiene sólo un valor histórico" (p. 40). Paz agrega que del apartado "Prosas varias" de Villaurrutia -se refiere a la edición de las Obras del FCE que en 1966 organiza Alí Chumacero-, lo mejor está constituido por apuntes autobiográficos, reflexiones "rápidas, incisivas e irónicas" (p. 42) cuya característica es la vivacidad de su propia conversación. Señala que ninguna de esas prosas sobresale y retoma las palabras de Chumacero al decir que son signos del gusto del poeta "por deambular en campos que no eran los suyos" (Paz, 2003, p. 42; Villaurrutia, 2004, pp. XXVI-VII). De hecho, Chumacero lee esta obra como ejemplo de la prosa resultado de influencias no comunes en el México de la época, sin atreverse a llamarla novela, relato o cuento, sino "ejercicio, en el cual la nostalgia divide honores con la inteligencia" (Villaurrutia, 2004, p. XXV). Pese a ello, el mismo poeta repara en que Villaurrutia recurre a la "cámara lenta" (p. XXVI). ¿Qué tan consciente es el comentario de Chumacero respecto de la presencia del cine en Villaurrutia? Porque precisamente una cámara cinematográfica media entre el lector y el cuento cinematográfico.

\section{FILIACIONES: NOVELA LÍRICA, CINE Y PÚBLICO}

Es Guillermo Sheridan (2015) quien repara en la filiación de las novelas líricas con A la sombra de las muchachas en flor de Marcel Proust, publicada en 1919 (cf. pp. 319-23). Esta relación llevaría a pensar en un proyecto conjunto de Owen, Torres Bodet y Villaurrutia; sin embargo, el mismo Sheridan reproduce la idea de que la unión entre los Contemporáneos es dada únicamente por "cierto rigor crítico" (Sheridan, 2015, p. 12; Keizman, 2016, p. 98).

Para Rosa García Gutiérrez (1997), Dama de corazones es un ejercicio personal de experimentación estética que se traduciría en la génesis de Nocturnos, "como si [Villaurrutia] intuyese que la prosa habría de ejercitarle y afinarle la pluma, aclararle las ideas, facilitarle su plasmación en un texto literario" (p. 263). Esta hipótesis cobra relevancia al considerar el carácter unánime del arte para los Contemporáneos. Y en esa línea García Gutiérrez lee las tres novelas, esto es, "como un programa narrativo comunitario expresamente grupal” (p. 261). 
Desde esta lectura, tanto la poesía como la dramaturgia (incluidos los experimentos teatrales de Ulises y Orientación) y las revistas (La Falange, Ulises o Contemporáneos) del "grupo" persiguen un fin común que implica la profesionalización de las artes, pero también la formación de público. Dado que Villaurrutia presta "minuciosa atención" (Potter, 2012 p. 131) a la composición y a la recepción de sus obras, es razonable que durante el proceso creativo tome en consideración al público (lector o espectador) que, a su juicio, debe poseer cierta formación. De ahí también la función pedagógica desarrollada en sus textos.

Respecto de la poesía, Sara Potter (2012) considera que en Villaurrutia la elipsis (como recurso poético, no lingüístico) requiere "la participación activa y la creatividad del lector" (p. 134), por lo cual una vez más es razonable la atención prestada en el proceso creativo ${ }^{3}$.

Respecto del cine, Villaurrutia ejerce esta función pedagógica en dos líneas. La primera interesándose abiertamente, igual que Torres Bodet, en la profesionalización de directores de cine y guionistas, a través de diversos ensayos donde considera que están forzados a aprender de las técnicas teatrales ${ }^{4}$. La segunda, directamente relacionada con su crítica cinematográfica, a saber, reseñas de películas publicadas en revistas de mayor alcance, Hoy y Así, entre 1937 y 1943. Crítica abierta y un poco desordenada al inicio, que con el tiempo gana en estructura y cierto léxico técnico. Incluso escribe guiones cinematográficos ${ }^{5}$ y participa en películas, la más famosa es Vámonos con Pancho Villa (1936), de Fernando de Fuentes.

Sobre la formación de público, de cierta manera Villaurrutia sigue la línea de su maestro Alfonso Reyes quien, como Martín Luis Guzmán en la época, se inclina por la promoción de la profesionalización del escritor, del intelectual y del crítico. En el Prólogo a la selección crítica Textos y pretextos de 1940, Villaurrutia (2004) anota:

\footnotetext{
${ }^{3}$ En el artículo, Potter establece una comparación entre Villaurrutia y John Cage en tanto creadores cuya consideración por el papel del público (lector o auditorio) es fundamental, pues sin él ni la elipsis ni el silencio funcionarían.

${ }^{4}$ Redacta además "Música, canto y cinematógrafo" (Villaurrutia, 2004, p. 955), que publica en Hoy el 5 de febrero de 1938; "Teatro y cinematógrafo" (p. 959), publicado en Cuadernos americanos en el número mayo-junio de 1947; y "Tiempo y espacio cinematográfico", publicado en dos entregas el 10 y 17 de diciembre de 1950 en Diorama de Cultura, sección dominical de Excélsior. La crítica cinematográfica de películas de actualidad es publicada en las revistas Hoy y Así, de 1937 a 1943, y recopilada por Miguel Capistrán (Ver Villaurrutia, 1970).

${ }^{5}$ En la revista El hijo pródigo, publica un guion cinematográfico titulado "La mulata de Córdoba", fechado el 15 de diciembre de 1945 y dedicado a Julio Bracho. El escenario cinematográfico del mismo guion lo realiza con Agustín Lazo, en la revista México en el arte, el 2 de agosto de 1948. Ninguno se lleva al cine.
} 
Mi intención al publicarlos no es otra que servir, en algunos casos, a los amantes de nuestra literatura, de nuestro arte, que no cuentan, por falta de notas y estudios críticos acerca de escritores contemporáneos, con muchos puntos de apoyo, de referencia o de controversia. (pp. 639-640)

Si bien se refiere a la literatura, piensa la función pedagógica para las artes en general, cuyos rasgos principales deben ser su unidad y composición. Ambos términos trasladados a su léxico crítico desde el teatro, donde inicialmente se relacionan con el nivel de representación escénica.

Como medio, el cine está presente en la obra villaurrutiana de manera pública a partir de $1926^{6}$, a través de su poesía, de sus ensayos sobre teatro y pintura y de sus comentarios a películas de actualidad publicados en Hoy y Así. Dada la irrupción del medio tecnológico en la cultura, Villaurrutia lo hace parte de su reflexión artística, inicialmente no como tema central, sino como una manifestación en ciernes que puede servirse de la plástica y la estética, de la pintura y el teatro. No obstante, la única ficción dedicada al cine e inédita hasta la compilación de sus Obras es "El amor es así...."

\section{CUENTO CINEMATOGRÁFICO COMO PROTOINTERMEDIALIDAD}

¿Qué conduce a pensar en este cuento como argumento o esbozo del guion de un proyecto mayor que Villaurrutia quisiera llevar al cine? Poco o nada. Mucho más sugerente es pensar que nunca tuvo la intención de hacerlo; que "El amor es así..." es el proyecto en sí, a medio camino entre la prosa, el cuento, el guion cinematográfico y la poesía, sucesión de imágenes proyectadas en la mente del lector-espectador. Villaurrutia construye un espacio intermedio -acaso protointermedialidad, tal como se habla de lo protocinematográfico-impulsado por su fascinación ante el medio tecnológico al asumir que abre novedosas posibilidades de narración.

Ralph Freedman (cf. Lozano Marco, 2011) define la novela lírica como un híbrido que usa la novela para aproximarse a la función del poema, por lo que quien la practica "reconcilia la sucesión en el tiempo con la acción instantánea de la lírica" (s.p.). Villaurrutia no solo utiliza la lírica y la no-

\footnotetext{
${ }^{6}$ En Reflejos (publicado originalmente por Ed. Cvltvra en 1926), aparece un poema titulado "Cinematógrafo" (Ver Villaurrutia, 1970), aunque el tema está más relacionado con el espacio físico que con las implicaciones tecnológicas y artísticas.
} 
vela, sino el cuento y el lenguaje cinematográfico para aproximarse a la función del poema y a la creación de imágenes hasta recrear instantes. A diferencia de otros escritores de la época recelosos del medio, Villaurrutia muestra fascinación por el cine porque ve una vía artística prometedora, nutrida de otras y en plena mutación.

De por sí, la novela lírica es intermedial. Ruth Cubillo Paniagua (2013) considera la noción de intermedialidad en tanto

la influencia mutua, la correlación o la interacción entre dos o más prácticas significantes, donde ninguna de las dos posee mayor jerarquía que la otra y que puede generar una redefinición de cada uno de los medios o prácticas implicados, así como nuestras formas de percepción de estos medios o prácticas. (p. 172)

La investigadora cita el monográfico que la revista de Estudios Culturales. Cultura, lenguaje y representación, de la Universidad Jaume I, dedica al tema y cuya presentación señala que la noción "se asocia con la difuminación de las tradicionales fronteras formales y de géneros propiciada por la incorporación de los medios digitales a las prácticas culturales" (Cubillo Paniagua, 2013, p. 172).

Se podría hablar de una protointermedialidad porque Villaurrutia no solamente referencia el cine, ${ }^{7}$ sino que después imita la técnica del cine en la escritura, la forma en que escribe es, se diría, cinematográfica, razón por la cual "El amor es así..." no puede ser nombrado solamente cuento. En Obras... (Villaurrutia, 2004), los editores deciden especificar el género de esa prosa, de modo tal que el lector se encuentra con "El amor es así...' Cuento cinematográfico", y esas palabras son resignificadas: un cuento que es cinematográfico, en oposición a un cuento de tema cinematográfico.

\section{Variación del tema}

La primera característica del cuento es la imprecisión en la fecha de escritura. El autor no data el cuento, y el lugar que ocupa en la compilación de su obra, después de la novela Dama de corazones, conduce a pensar que lo

\footnotetext{
${ }^{7}$ Aunque sí lo hace en un primer momento porque se sirve del cine únicamente como medio, su práctica muta al descubrir en el cine otras posibilidades.
} 
escribe entre $1926^{8}$ y 1928 . También a 1926 corresponde el poema "Cinematógrafo", incluido en Reflejos. Sin embargo, Aurelio de los Reyes (1983) se aventura a decir que pertenece a los años cuarenta porque la trama pareciera corresponderse con la etapa del cine sonoro (p. 182). Su hipótesis es plausible solo si se considera la fecha de publicación de la compilación del también Contemporáneo Bernardo Ortiz de Montellano, sobre relatos con motivos cinematográficos, en 1940.

Ante este panorama, no obstante, leer "El amor es así..." como variación de Dama de corazones abre las posibilidades de establecer una íntima relación entre el cine y la escritura (en prosa y verso), en un espacio protointermedial también colmado de crítica e ironía.

Instalado en la modernidad, Villaurrutia hace uso de los recursos a su alcance, observa su derredor y lleva a su obra dispositivos que dan cuenta de los años convulsos para el arte y para el país, "ambiente mudable de la Ciudad de México" (Potter, 2012, p. 135). Si el cuento no es magistral en su argumento, sí revela una irónica problematización de la época y del arte mucho mejor apreciada desde una visión conjunta de la producción cultural villaurrutiana (crítica, ensayística y poética), de forma tal que esta historia puede revelar también su postura teórica, cultural y política frente al arte. Son los años en que se sientan las bases de la nación moderna y se intenta dar forma a la literatura mexicana. Basta recordar la pugna entre estridentistas y Contemporáneos (cf. Ignacio Sánchez Prado, 2007 y 2009).

Precisamente acerca de esa nación moderna prodigada por el discurso porfirista, "El amor es así..." es también una lectura de las transformaciones urbanas (y el crecimiento desigual) en el país en los años posteriores a la Revolución. Fiel a sus principios, Villaurrutia nunca habla de la política social, sin que ello signifique la ausencia de una postura9 ${ }^{9}$. Las publicaciones en las que participa y los temas que prefiere son ya una toma de partido y una visión de mundo.

La descripción de la ciudad, coprotagonista del cuento, invita a un desplazamiento similar al cinematográfico. El autor aproxima al lector a la lectura y a los personajes mediado por su lente. Irrumpe en la vida de estos personajes para contar su nada peculiar historia, porque, al fin y al cabo, "el

\footnotetext{
${ }^{8}$ Es el año por el que opta la investigadora Miriam Gárate (2012).

${ }^{9}$ Más bien suele hablarse de la postura apolítica de Villaurrutia y los Contemporáneos, aunque tal postura sea aparente y esté más relacionada con permanecer ausente de asuntos públicos. La lista de quienes han dedicado líneas al tema es larga, entre ellos Rosa García Gutiérrez (1997) -artículo aquí citado- y Guillermo Sheridan, principalmente en Señales debidas (Ver Sheridan, 2012).
} 
amor es así..." Dicho de otra forma, se trata de un melodrama característico de la producción cinematográfica mexicana de la época, según Carlos Monsiváis (2006), pero con un tinte policíaco que aporta sentido del humor y del absurdo. Una anticipación de los posteriores años del cine nacional.

La historia de amor despliega sucesos a raíz del encuentro entre un joven migrante de Jalisco ${ }^{10}$-recién instalado en la periferia de la ciudad de México con sueños de triunfo- y una habitante de una casa de huéspedes. Desde las primeras líneas el narrador omnisciente se acerca hasta detenerse en las vidas que escoge contar. Casi al azar, como sucede con los protagonistas de La ilusión viaja en tranvía de Luis Buñuel, el narrador selecciona estos personajes por sus características, pero también para "entretener" al lector-espectador. La referencia a esta cinta es casi automática por los sueños que en ambas narraciones la ciudad, como personaje, habilita o clausura. En el guión de Mauricio de la Serna que inaugura la película de Buñuel se escucha:

México, gran ciudad como tantas del mundo, es teatro de los más variados y desconcertantes sucesos que no son sino las pulsaciones de su diario vivir, no obstante su trascendencia. Millones de hombres y mujeres trenzan, hora tras hora, sus historias fugaces y sencillas. Sus actos y palabras se encaminan siempre a la realización de un sueño, de un deseo, de una ilusión.

Unidas todas ellas forman el colosal enjambre de la vida citadina. Al azar enfocamos la atención en un rincón cualquiera de nuestra gran ciudad y así, esta película ha de ser una anécdota más, sencilla y casi trivial, de la vida en el sector laborioso y humilde que forman la gran masa. El de las gentes que viajan en tranvía. (Orive Alba, A. y Buñuel, L., 1954)

Mientras en la escritura de Villaurrutia se lee: "En la ciudad de México se pasa bruscamente del centro iluminado, activo, a los barrios pobres, apagados, lentos. Horacio vive en un barrio pobre. Es joven y fuerte, pero tiene, al mismo tiempo, cierta propensión a la melancolía" (Villaurrutia, 2004, p. 597). El escritor presenta el panorama y baja de inmediato hasta donde se encuentra su personaje. Su foco está puesto, se diría, en la gente que vive en la ciudad y escapa a través del cine. La rapidez es una constante, las frases cortas y los puntos y seguido marcan el ritmo del relato, así como

\footnotetext{
${ }^{10}$ Estado mexicano ubicado en la zona oeste.
} 
los constantes cambios ${ }^{11}$. Muchos verbos y pocos adjetivos hacen que los acontecimientos se sucedan uno tras otro y que sea el propio lector quien opte por interpretarlos.

Los personajes responden a arquetipos del melodrama, pero el autor no los deja en paz, sino que los presiona, tensa y lleva al extremo. Sin que los personajes femeninos, María y Luisa, sean el ideal de mujer promovido por la sociedad mexicana de la época, pues ambas "pecan" en algún momento, el relato es atravesado por frases que marcan claramente la distancia entre una y otra. Luisa, por ejemplo, "tiene un pasado vulgar y triste. El hombre que la sedujo la abandonó pronto [...] le quedó el gusto por las diversiones, por los vestidos vistosos" (p. 597). Dedicada a la vida alegre de los cabarets, el personaje tiene rasgos distintivos que se leen en consonancia con la época. Por ejemplo, "quiere ser o aparentar algo más que las obreras del taller donde trabaja [y] sacrifica cualquier cosa por contar con algún dinero" (p. 597). Cierto, hay una descripción que puede ser fácilmente caricaturizada, pero es funcional.

Los personajes son definidos a partir de la oposición. La dicotomía del bien y del mal funciona: la Dama doble cara (reina de corazones) se presenta. María, a diferencia de Luisa, vive "una vida monótona (...). A veces, un breve paseo por las ferias y carpas; los domingos, al cine (p. 597). Si en Dama de corazones es el protagonista quien debe escoger entre dos mujeres, en "El amor es así..." es la protagonista quien se ve entre dos hombres. La repetición y variación de Villaurrutia lo lleva a cambiar el papel protagónico para que sea la mujer quien decida, aun cuando, como se sabe, no importa si María elige a Horacio o a José, pues lo trascendente es la variación del tema, la experimentación con la lengua y el ritmo, los silencios y la disposición de alternativas. A diferencia de la novela lírica, en la trama del cuento no hay un deslizamiento hacia lo colectivo; en cambio, existe una lectura de la travesía/desplazamiento del campo a la ciudad o, con mayor precisión, de los suburbios al centro de la ciudad, donde existen otras posibilidades de diversión y el tedio no invade. El sujeto móvil es el fundamento del cuento.

Por si no bastara esta aproximación ni las vistas de la ciudad, Villaurrutia incluye al cine como diversión presente ya en la cotidianidad de seres comunes en la urbe. El lector-espectador intuye que el escritor prepara un

\footnotetext{
${ }^{11}$ Tanto las imágenes como la respiración son temas que ocupan a Villaurrutia. Es común encontrar alusiones a ambos temas en sus distintas reflexiones. Ver "Variedad" (Villaurrutia, 2004, pp. 605-615).
} 
final feliz para María, de sanas costumbres y sin grandes aspiraciones salvo la de encontrar el amor, por el cual bien vale la pena sufrir. La vuelta de tuerca de Villaurrutia es que Luisa, pese a ser bailarina y llevar una vida de cabaret, no termina con final desolador y solo imagina que su vida continúa sin mayor sobresalto descubriendo incluso una dulzura soterrada. José, el enamorado no correspondido de María, atónito ante el sufrimiento de su amor y ante la fidelidad a Horacio, se lleva una esperanzadora lección de vida, pues puede constatar que el amor es, tal como el relato bíblico, "sufrido, es benigno; el amor no tiene envidia, el amor no hace nada indebido, no

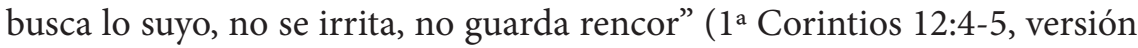
Reina-Valera 1960).

La referencia bíblica no es azarosa. Villaurrutia se encuentra lejos de la religiosidad, pero cerca de "esferas de experiencia", como las llama Nick Piombino (como se cita en Potter, 2012, p. 140), cuyos elementos cristianos están relacionados con sus obsesiones temáticas: la muerte, el amor, los sueños. Ello es más evidente en sus "Primeros poemas" (Villaurrutia, 2004, pp. 3-25), escritos alrededor de 1920; de ahí que no sea extraña la relación temática y referencial entre estos y "El amor es así...”.

En el espacio del cuento, todos los personajes sueñan de manera literal o tienen sueños: María rechaza a José porque "tiene sus sueños" (p. 597) y después "Se arregla mejor, está más despierta. Tiene esperanza de encontrar a aquel hombre en que soñó la noche del encuentro" (p. 598); Horacio se desanima al enterarse del embarazo de María porque sueña con una mejor vida: "Él aspiraba a dejar su plano social y a alcanzar otro" (p. 599); mientras que Luisa vive "soñando despierta" (p. 597); y finalmente José sueña con que María le corresponda.

Sin duda esto constituye también una variación de su obsesión temática, otra forma de explorar lo mágico y abrir caminos. Casi tantos como los que evocan los puntos suspensivos del título que hacen recordar los poemas tempranos. Si en estos, como sugiere Potter (2012), tanto los espacios como los puntos suspensivos interpelan al lector y dan pie a interrogantes, en el cuento interpelan al lector hasta obligarlo a prestar atención a la hipótesis de lo que el poeta considera amor, desplegado en el relato. Si Villaurrutia dice "El amor es así...", el lector piensa y responde: ¿cómo? Y el narrador comienza su historia. Los puntos son un recurso elíptico, tanto como los espacios y los silencios, que conducen a reconsiderar el tema de la respiración en un poeta como Villaurrutia.

Temáticamente la melancolía también está presente. En Los orígenes del cine en México, Aurelio de los Reyes (2013) descubre que a inicios del 
siglo XX el índice de alcoholismo y suicidio es alto y frecuente, pero lo más interesante es que ambos fenómenos son atribuidos, por algunos, a la modernidad y al progreso. No son extraños el desarraigo y la melancolía a los que Horacio es propenso, asociados a su personalidad, pero también al desplazamiento de la provincia a la ciudad, la añoranza del cobijo familiar, la ausencia del bienestar prometido por la capital o a la ausencia de una experiencia amorosa intensa, antes de María.

Las circunstancias, no obstante, propician la madurez de Horacio y María, y en pocas líneas se puede leer una micronovela de formación. Ella descubre su deseo y sensualidad, y los explota; conoce hombre, conoce la "alegría de vivir" (Villaurrutia, 2004, p. 599) y también la decepción amorosa. Él descubre las argucias del encanto masculino y de la virilidad, también cuánto vale la mentira, la traición y el abandono. Tras el gozo experimentado llegan las desavenencias: "Descenso en la vida de Horacio y María. Desacuerdo. Discusiones." (p. 599).

Horacio abandona a María y a su hijo en una especie de negación del error cometido al desviar su camino. El hijo enferma y ella, sin dinero, está a punto de ceder a la tentación del dinero fácil en el cabaret. La presunta infidelidad de María es más poderosa y desata los celos de Horacio. Entonces una comedia de enredos irrumpe en el relato: enloquecido y borracho, Horacio va a casa y "vacía la pistola al busto de su mujer en la cama" (p. 600). Después se entrega a la policía, que descubre el "homicidio" de un bulto de almohadas; de cualquier forma, Horacio termina detenido por portación de arma. Los días de angustia de María terminan cuando su amado sale del encierro y acude a su encuentro. Luisa y José son espectadores de esta historia con final feliz donde el amor triunfa una vez más.

Los desplazamientos de los personajes por la ciudad la van trazando en la mente del lector. Los domingos de cine, las noches de cabarets baratos, la lentitud en los barrios pobres sin energía eléctrica, los peligros de la oscuridad y la lejanía del centro, los cuartos de solteros y las casas de huéspedes para señoritas, los vestidos vistosos y vulgares, las miradas furtivas entre hombres y mujeres, la timidez y la osadía, la asiduidad de mujeres galantes a las cantinas.

A inicios del siglo XX, la literatura y el cine se interesan en las historias cotidianas de la gente común que, de no registrarse, se perderían fácilmente. Historias empujadas por el drama cotidiano del cambio de las ciudades, de los movimientos migratorios del campo a la capital, de los desplazamientos desde ciudades pequeñas a otras más grandes y con mayor desarrollo. José Luis Romero (2007) señala que no todos los migrantes 
provienen del campo, muchos "se arrancaban de pequeñas o medianas ciudades que acentuaban su decadencia” (p. 323), dispuestos a participar de la "nueva" vida colectiva con atractivas promesas de progreso.

Así, tras la Primera Guerra Mundial las ciudades comienzan a masificarse con gente de impreciso origen, ocupada mayoritariamente en servicios o en oficios, como las costureras de Villaurrutia. La explosión urbana es una ofensiva del campo sobre las ciudades que transforman las perspectivas de Latinoamérica. Las ciudades son promesas de empleo y de servicios, de un bienestar que no se encuentra ya en el campo. Pero la realidad es que la publicidad del bienestar de la urbe en radio y televisión no llega a todos. Los migrantes con anhelo de ser empleados en las recién instaladas industrias encuentran a muchos iguales para los que no hay cabida. En apariencia, es la elección del Horacio "joven y fuerte" (Villaurrutia, 2004, p. 597) que va de provincia a la ciudad de México para un mejor vivir. A cambio de ese sueño, encuentra un remedo de vida en un barrio pobre. María como costurera y él sin empleo ni oficio, forman parte de un grupo social al margen de los beneficios de la promesa del progreso en el México postrevolucionario.

\section{CONCLUSIÓN}

Los años que median entre "El amor es así..." (considerando 1926 año de su redacción) y La ilusión viaja en tranvía sirven para que la ciudad de México se modifique, pero por el cada vez más común desarraigo cultural a raíz del éxodo del campo o de los suburbios. La literatura y el cine muestran la dimensión del proceso de modernización y progreso del que los gobiernos no cesan de hablar, pero que los expulsados difícilmente ven.

A diferencia de escritores como Horacio Quiroga, Jorge Luis Borges, César Vallejo, Carlos Noriega Hope o Bernardo Ortiz de Montellano ${ }^{12}$, quienes expresan su fascinación por el cine a través de la ciencia ficción y las historias fantásticas de amor, o de encuentros con estrellas hollywoodenses, Villaurrutia ilustra en este cuento cinematográfico parte de la violenta cotidianidad que ya se deja ver en las nuevas tierras arrasadas por la modernidad.

\footnotetext{
${ }^{12}$ Miss Dorothy Phillips, mi esposa (1919) en el caso de Quiroga; Che Ferrati, inventor (1923), en el de Noriega Hope; y "Noches de Hollywood" [en la antología Cinco horas sin corazón (1940)], de Bernardo Ortiz de Montellano.
} 
Es muy difícil precisar si alguna vez el autor intenta llevar el cuento a la pantalla grande, como lo hace con el también inacabado proyecto "La mulata de Córdoba". Lo cierto es que su acercamiento temático a la ciudad y a los desplazados habla de una visión en conjunto de los acontecimientos en el México de los años veinte, tras el vendaval revolucionario y los afanes de construcción de la nación. Acaso el argumento le habría alcanzado para hacer un cortometraje o un videoclip como los actuales.

Por lo anterior es que la lectura de este cuento cinematográfico no debe estar sino relacionada con la unidad (total) de la obra villaurrutiana. Esto es, como la variación del tema iniciado con la novela lírica Dama de corazones asociado, a su vez, con la variación de otras obsesiones/pasiones del autor: el amor, la muerte, los sueños, el cine, la música, los silencios, la respiración y hasta la formación de público, cuyo encuentro no solo material sino semiótico y cultural, protointermedial, ayuda a aproximarse con ojos distintos al cuento cinematográfico.

Ya en los años treinta, Villaurrutia clausura la posibilidad de la ficción cinematográfica; en cambio, publica su crítica de 1937 a 1943, esforzándose por formar al público a través de sus ensayos de poesía, teatro, pintura o cine, para favorecer su participación activa. Congruente consigo, Villaurrutia piensa en influir en dicho público y en cualquiera dedicado a las artes, no solo para remover las cuerdas sentimentales sino para generar una "intención estética" (Villaurrutia, 1970, p. 264), como sugiere a propósito del cine que ve y juzga.

\section{REFERENCIAS}

Cubillo Paniagua, R. (2013). La intermedialidad en el siglo XXI. Diálogos. Revista Electrónica de Historia, 14(2), 169-179.

De los Reyes, A. (1983). Los Contemporáneos y el cine. Anales de Instituto de Investigaciones Estéticas, XIII(52), 167-186 [en línea] Disponible en http:// www.analesiie.unam.mx/index.php/analesiie/article/view/1184/1171

De los Reyes, A. (2013). Los orígenes del cine en México (1896-1900). Ciudad de México, México: Fondo de Cultura Económica.

Gárate, Miriam V. (2012). Películas de papel: Cine y literatura en dos textos latinoamericanos de la década del veinte, en VIII Congreso Internacional de Teoría y Crítica Literaria Orbis Tertius, 7-9 de mayo, La Plata. En Memoria Académica. [En línea.] Disponible en http://citclot.fahce.unlp.edu.ar/viiicongreso

García Gutiérrez, R. (1997). Dama de corazones de Xavier Villaurrutia en la 
génesis de los Nocturnos. Anales de Literatura Hispanoamericana, 26(2), 259-277.

Lozano Marco, M. A. (2011). La formación de la novela lírica (1901-1910). Alicante: Biblioteca virtual Miguel de Cervantes http://www.cervantesvirtual.com/obra-visor/la-formacion-de-la-novela-lirica-1901-1910/html/ dc4748d2-daf3-11e1-b1fb 00163ebf5e63_5.html

Keizman, B. (2016). La escena de las novelas líricas en la trayectoria de los Contemporáneos. En B. Keizman y C. Vergara (eds.). Profundidad de campo. Des/encuentros de cine-literatura en Latinoamérica (pp. 97-112). Santiago, Chile: Metales Pesados.

Monsiváis, C. (2006). Aires de familia. Cultura y sociedad en América Latina. Barcelona, España: Anagrama.

Orive Alba, A. (productor) y Buñuel, L. (director). (1954). La ilusión viaja en tranvía [cinta cinematográfica]. Ciudad de México, México: Clasa Films SA.

Paz, O. (2003). Xavier Villaurrutia en persona y obra (tercera reimpr.). Ciudad de México, México: FCE.

Potter, S. (2012). Nocturnos silenciosos y vacíos fructíferos: El sonido y el espacio en la poesía de Xavier Villaurrutia. Confluencia, 27(2), 130-145.

Romero, J. L. (2010). Latinoamérica. Las ciudades y las ideas. Buenos Aires, Argentina: Siglo XXI.

Sánchez Prado, I. (2007). Vanguardia y campo literario: la Revolución mexicana como apertura estética. Revista de crítica literaria latinoamericana. Año XXXIII, 66, 187-206.

Sánchez Prado, I. (2009). Naciones intelectuales. Las fundaciones de la modernidaa literaria mexicana (1910-1959).West Lafayette, Indiana, Estados Unidos: Purdue University Press.

Sheridan, G. (2012). Señales debidas (primera edición electrónica). Ciudad de México, México: FCE.

Sheridan, G. (2015). Los Contemporáneos ayer (primera edición electrónica). Ciudad de México, México: FCE.

Villaurrutia, X. (1970). Crítica cinematográfica. Recopilación, selección, introducción y notas de Miguel Capistrán. Ciudad de México, México: Dirección General de Difusión Cultural UNAM.

Villaurrutia, X. (2004). Obras: poesía, teatro, prosas varias, críticas. Prólogo de Alí Chumacero; recopilación de textos Miguel Capistrán, Alí Chumacero, Luis Mario Schneider. Ciudad de México, México: FCE. 